\title{
Ecosystem Under Construction: An Action Research Study on Entrepreneurship in a Business Ecosystem
}

\author{
Marikka Heikkilä and Leni Kuivaniemi
}

\author{
"All great things are based on a series of small things, and all") \\ the small things need hard work. \\ Kimmo Rauhala \\ Growth venturer and entrepreneur \\ Owner of Suomen Liikunta-apteekki \\ (Finnish Sport Pharmacy)
}

\begin{abstract}
In recent years, we have seen increasing interest in new service concepts that take advantage of the capabilities of business ecosystems instead of single companies. In this article, we describe how a business ecosystem begins to develop around a service business idea proposed by an entrepreneur. We aim to recognize the different domains of players that are or should be involved in the ecosystem while it is under construction. The article concludes with an ecosystem model consisting of six sub-ecosystems having different change drivers and clockspeeds.
\end{abstract}

\section{Introduction}

Today, we see a lot of new services and innovative business ideas that mix the traditional boundaries of business sectors and of companies. Innovations can be found in the form of new products or services, cost-reducing process improvements, or innovative business models and methods. Many practitioners point out that it is rather easy to come up with new ideas, but the real challenge is in putting them into practice. This task is especially demanding when innovations occur outside the exclusive control and the supporting mechanisms of traditional business firms (Muegge, 2011; timreview.ca/ article/495). Instead, an ecosystem consisting of multiple expertises, capabilities, and resources should be created around the innovation.

In our previous studies (Heikkilä, 2010; tinyurl.com/ $346 \mathrm{kgel}$ ), we observed that the expansion of a business ecosystem follows a process of collaborative business modelling consisting of two parallel processes: i) the systematic analysis, improvement, and adjustment of a business model and its components and ii) the organizational change-management process. That is, at the same time as the business model is being developed, a substantial amount of effort has to be put into change management, to select the collaborators and escort the partners to harmonize the network strategy, to synchronize its operations, as well as to evaluate the feasibility of the operational business model. In this article, we concentrate on the very first tasks of change management, setting the scene, and selecting the players. We explore how an ecosystem evolves through a case study of physical activity prescriptions. The aim is to recognize the different domains of players that are or should be involved in the ecosystem under construction.

The remainder of the paper is organized as follows. In the next section, we review the existing literature on business ecosystems. Thereafter we present the case study and draw some conclusions from the case. We end the article with a summary, contributions and limitations of this study, and concluding remarks and suggestions for future work. 


\section{An Action Research Study on Entrepreneurship in a Business Ecosystem}

\section{Marikka Heikkilä and Leni Kuivaniemi}

\section{Relevant Research on Business Ecosystems}

Recently it has become quite common to conceptualize business networks by comparing them to biological ecosystems (Iansiti and Levien, 2004a; tinyurl.com/ bvn8zkv). Similar to a biological ecosystem, a business ecosystem is formed by large, loosely coupled networks of entities. These entities such as firms, organizations, entrepreneurs, etc. interact with each other and the health and performance of each actor is dependent on the health and performance of the whole. That is, the actors are simultaneously influenced by their own capabilities and their interaction ties with the other players in the ecosystem (Håkansson and Ford, 2002; tinyurl.com/bwq298m). The trend of many firms looking for new opportunities beyond their existing industry explicates (Solaimani et al., 2010; tinyurl.com/czoh69o) that contemporary ecosystems are not restricted to any single industry but cross a variety of industries (Moore, 1993; tinyurl.com/cygzy60).

Perhaps the major difference between the concepts of business ecosystems and business networks is in the variety of actors. Typically, business networks are considered as groups of firms co-operating in designing, producing, and delivering products to customers. Business ecosystems, in turn, include partners and subcontractors but also complementors, competitors, customers, and potential collaborator companies, as well as public bodies, local incubators, investors, and even research institutes and universities (Moore, 1998; tinyurl.com/7cghul7). Each ecosystem typically encompasses several domains that it shares with other ecosystems. It is expected to have a heterogeneous structure, with actors adopting dramatically different roles that influence different aspects of the stability and productivity of the whole. This especially is the case when complex knowledge is needed and the sources of expertise are widely dispersed (Powell et al., 1996; tinyurl.com/6t4btal).

Innovative ideas may come from large corporations or organizations, but often they are suggested and pushed forward by entrepreneurs, or in spin-off companies. Many of the seeds of new businesses die young, but perhaps are revitalised at some later date when more fertile ground is available - this includes an ecosystem that supports the growth. As Iansiti and Levien (2004b; tinyurl.com/7t4xgvn) point out, it is merely an academic exercise to try to draw the boundaries of an ecosystem. Instead, it is more helpful to recognize the types of organizations or players that should be involved in order to provide a suitable environment for new business to prosper.

Moore (1993; tinyurl.com/cygzy60) describes a business ecosystem as consisting of layers (Figure 1), which correspond to differing levels of commitment to the business. The core business layer consists of the parties forming the heart of the business. In traditional busi-

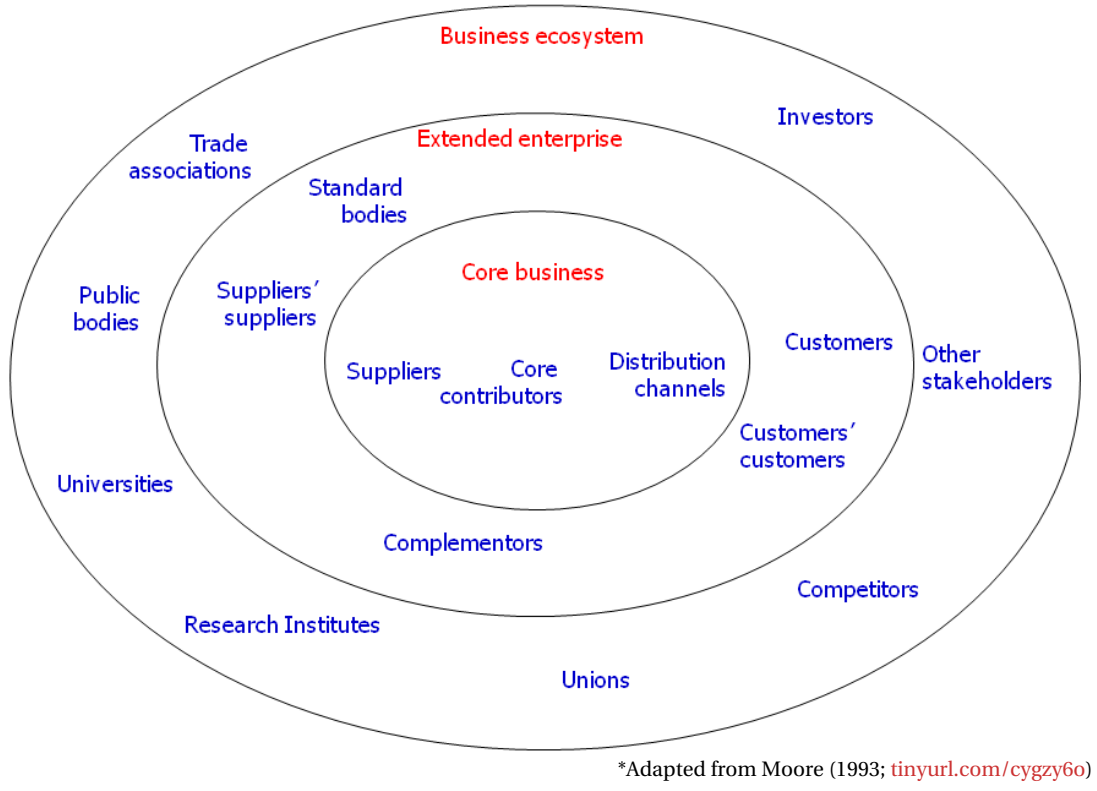

Figure 1. The layers of a business ecosystem* 


\section{An Action Research Study on Entrepreneurship in a Business Ecosystem}

\section{Marikka Heikkilä and Leni Kuivaniemi}

ness, this layer would be run by a single company or the supply chain would be coordinated by the focal company. Alternatively, it can also be formed by a network of several companies each taking care of part of the core business. The next layer, the extended enterprise, widens the view of the business supply chain to include the customers, complementors and second-layer suppliers, as well as standard-setting bodies in the particular field of business. The outermost layer adds trade associations, unions, universities and other research bodies, investors, and stakeholders to the business ecosystem. Even though they are perhaps not directly involved in the business operations, these parties may have a significant effect on the success of the business.

\section{Pragmatic, Abductive Action Research}

"Fighting Low Activity by Business Creation" (LA; fighting la.com/research) is a research project focusing on preventing health problems that typical of Western industrialized countries (e.g., obesity, Type 2 diabetes) by developing significant global export service products based on Finnish expertise in the domains of health, exercise, and well-being. These service innovations are turned into new service and e-business models that are exploited by a network of new ventures and corporations, and they are spread with help of the supporting ecosystem. This ecosystem is expected to have a significant impact on public health.

Our research method is action research (tinyurl.com/ 2rarbb), where researchers actively participate in the business decisions by producing knowledge for the ecosystem players. Whereas other research methods seek to study organizational phenomena but not to change them, the action researcher is simultaneously studying the phenomenon and creating organizational change (Heikkilä, 2010: tinyurl.com/7f2g6ze; Aspegren et al., 2011: tinyurl.com/cn2sxwp).

Action research is an established research method in social sciences, and it builds on a pragmatist philosophy (Baskerville and Myers, 2004 tinyurl.com/8xqaeos). In pragmatism, the investigator and the research object are assumed to be interactively linked so that the findings are literally created as the investigation proceeds (Guba and Lincoln, 1994; tinyurl.com/bl4kgyh).

As action researchers, we are actively taking part in building the supporting ecosystem that we call an Ecosystem under Construction (EuC), which is the object of the study described in this article. We aim to make purposeful use of propositions, models, or theories, and to question whether they are useful in practice "in the sense of helping people to better cope with the world or to create better organizations" (Wicks and Freeman, 1998; tinyurl.com/bt23uno).

Our theoretical reasoning is moving back and forth between empirical discovery and theory in abductive manner (Paavola, 2006; tinyurl.com/cg26esw). Even though it has been heavily criticized, abduction is seen as a method to test new ideas or to make sense of new situations (Richardson and Kramer, 2006; tinyurl.com/ cblzcmq), which is the case in the creation of an ecosystem. The original theoretical framework is successively modified, partly as a result of unanticipated empirical findings, but also because of theoretical insights gained during the process (Dubois and Gadde, 2002; tinyurl.com/d9bu5vb). By helping to create the EuC, which combines partners and researchers with previous knowledge and understanding from several complementing areas, such as business, law, information systems, sports, and medicine, the ecosystem can help to provide new theoretical explanations and practical methods to find potential cures for the western world's problem of meagre physical activity.

\section{Case Study: Physical Activity Prescriptions}

The case example examined in this article is "physical activity prescription", a service innovation in preventive healthcare. The idea of boosting the physical activity of patients with prescriptions had been suggested by several researchers in the late 90s. The first pilots were carried out by public instances (marked as Phase 0 in Figure 2). The adoption of the sports prescriptions however, died down after the public financing ceased.

Phase 1 presents the new start, where the development is driven by an entrepreneur who has invested a lot of time in creating and promoting a business model requiring close collaboration of several companies. Figure 2 illustrates how previously the ecosystem consisted of mainly the most outer layer: universities and research institutes working with several unions and associations. In Phase 1, the ecosystem-building started from the core, with partners from a university and a funding institute. Phase 1 is led by an entrepreneur who has years of experience in the field and has knowledge of the research projects on physical activity prescriptions. Even though physical activity prescriptions have been trialled before, this business proposal is the first one that also gives financial incentives for the companies to provide the service. 


\section{An Action Research Study on Entrepreneurship in a Business Ecosystem}

\section{Marikka Heikkilä and Leni Kuivaniemi}

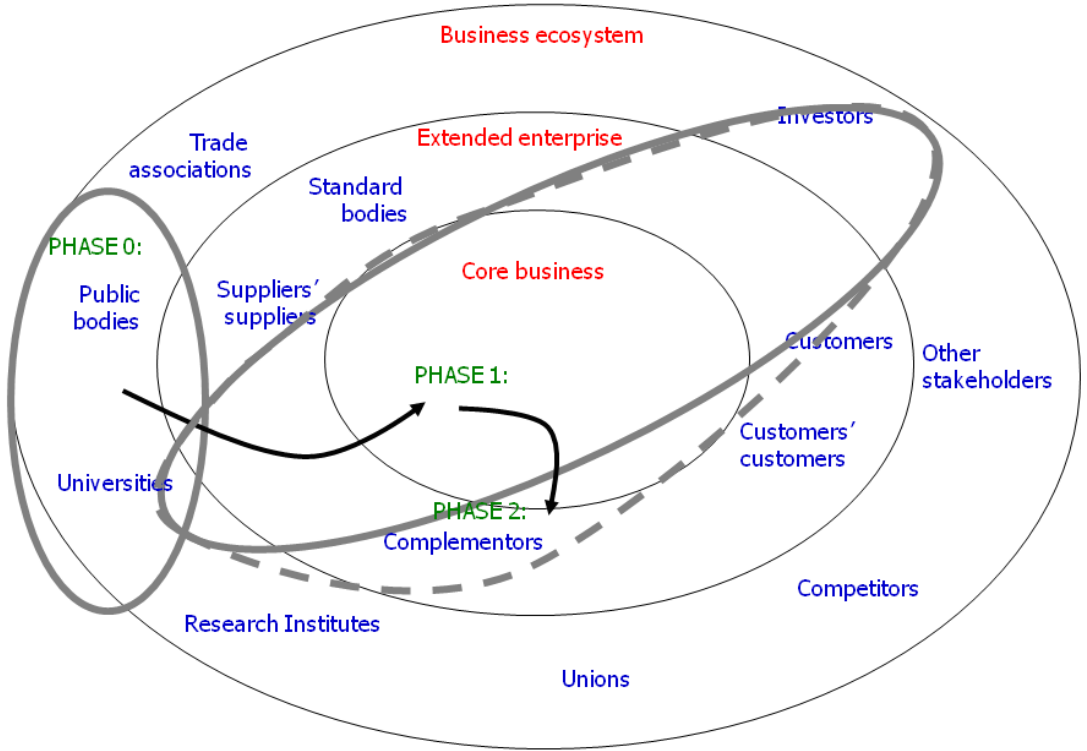

Figure 2. Evolution of the case ecosystem

\section{Key players}

The entrepreneur built the core of the around a network of companies. He saw that three parties are needed to guarantee the viability of the business:

\section{Private medical clinics}

\section{Pharmacies}

\section{The entrepreneur's own company}

Well-known private medical clinics provide credibility and critical mass. Initially, there were several prospects for the core partners, and those that had the most interest in the business idea were met in person. After negotiations, the leading private medical centre in Finland, Terveystalo (terveystalo.com/en/), was selected as a core contributor. Its core assets are doctors and a large customer base: the company has over 2,000 practitioners providing occupational healthcare in more than 150 locations. It also has the customer contacts of companies that purchase occupational health services for their employees. This relationship provides a good fit with the planned business model in which occupational healthcare patients are considered to be the most important segment of the new service. The role of the medical clinic in this business is to prescribe physical activity to its patients, especially within occupational healthcare.
Easy access and continuance of customer relationships can be guaranteed via pharmacies located near the customers. In Finland, there is at least one pharmacy in each community; in most communities there are multiple pharmacies. Most of the pharmacies are privately owned. The activities of pharmacies are controlled with licences provided by The Finnish Medicines Agency, a central administrative agency operating under the Ministry of Social Affairs and Health. Currently the majority of pharmacies' turnover comes from prescription drugs, but most pharmacies are seeking business opportunities to provide additional services. Pharmacies seem to have a good chance of success with their new strategy because a recent survey shows that customers are highly satisfied with pharmacy services (Apteekkariliitto, 2010; tinyurl.com/bo5omlf). After negotiations, a chain of 64 privately owned pharmacies, Avainapteekit Ltd. (avainapteekit.fi) joined the team. Their task in related to physical activity prescription is counselling and ongoing measurement of the improvements in the physical health of the patients.

The entrepreneur's own company (Finnish Sport Pharmacy) coordinates the operations. Whereas in previous experiments the researchers and public instances were leading the formation of the ecosystem, in this case the leader is the entrepreneur. His company is focusing on exactly those issues pointed out in previous trials as the most critical to success. The entrepreneur plays the 


\section{An Action Research Study on Entrepreneurship in a Business Ecosystem}

\section{Marikka Heikkilä and Leni Kuivaniemi}

main role in the creation of a fluent process that fits with the daily practice of practitioners and customers. He will provide an electronic prescription system that makes this process possible. He will also provide training to the doctors and pharmacists, which is needed for this new service. Also a large pharmaceutical company in the Finnish prescription and OTC (over the counter) market, ratiopharm Oy (ratiopharm.fi), is committed to helping train practitioners.

\section{Business model}

The "value add" in the new business model does not come from automation of the processes but from an entirely new process consisting of tasks carried out in multiple organizations. The process starts at a medical clinic, where the doctor prescribes medicines and physical exercise to the patient suffering from "wealth diseases". As the patient goes regularly the pharmacy for the medicine, the pharmacist measures their physical health and provides advice on how to improve it further. These measures are also available to the doctor when the patient is coming to the next check-up.

The business model requires information systems that facilitate and support this process (Mooney et al., 1996; tinyurl.com/cau7sbc). Currently, there are no information systems or measurement equipment in place that would transfer necessary information between the partners. That is why Phase 2 of the ecosystem-construction process, which is now underway, involves business negotiations with information systems providers and health monitoring equipment suppliers. Information technology is actually the major cost issue to solve before a proof of concept can demonstrate whether the business model is fiscally sound. For proof of concept, a minimalist prototype or pilot is needed to demonstrate how the business idea will play out in the real world and why all the core companies are needed to provide the services.

\section{Ecosystem sub-sectors}

In this case study, based on previous literature and on workshops where the business model was discussed, we added the actual names of the potential players to Figures 1 and 2. Currently, the challenge in boosting the growth of the ecosystem is how to recognize who are the next actors or areas that should be contacted and involved in collaboration. To overcome this challenge, it is useful to divide the ecosystem map into differing subsectors as we have done in Figure 3. The sectors are recognized from business modelling literature. Business model articles typically list external forces that affect the success of the business. These forces include competition/co-opetition, policies and the legal environment, social or technological change, research insights, and changes in customer demand (Nalebuff and Brandenburger, 1996: tinyurl.com/7jjllcb; eFactors, 2002: tinyurl.com/cyv3jxo; Hoffner et al., 2004: tinyurl.com/7a72l3s; Osterwalder, 2004: tinyurl.com/cx9smc7).

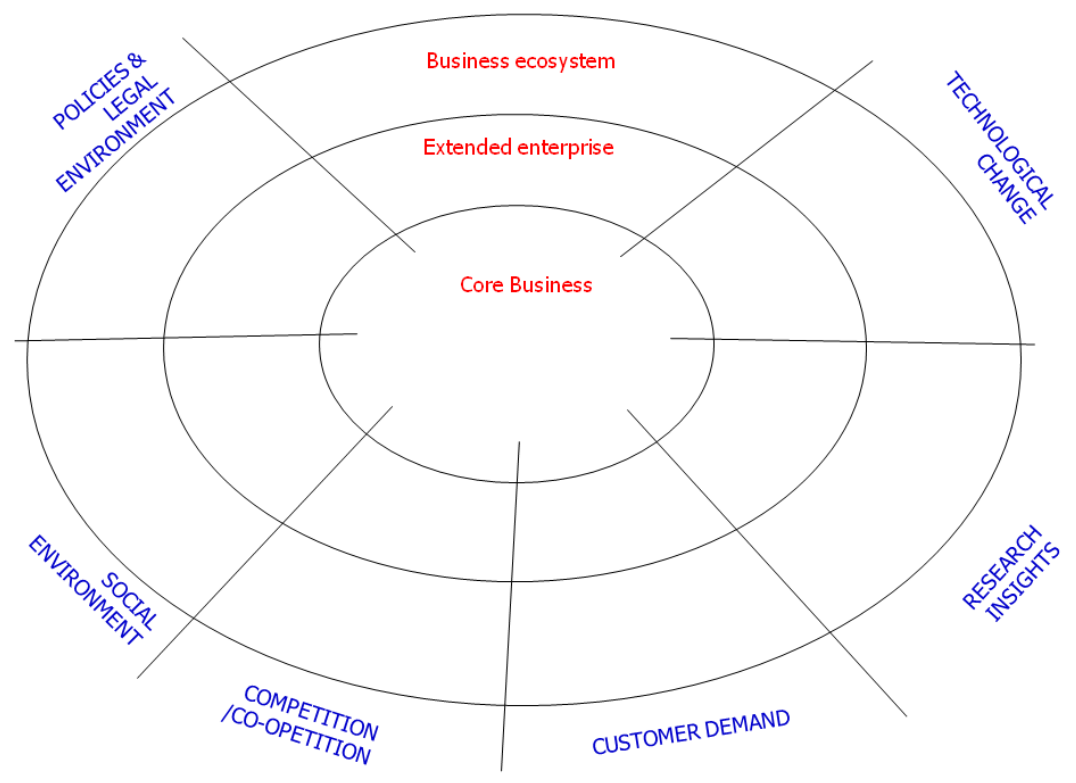

Figure 3. Sub-ecosystems within the business ecosystem 


\section{An Action Research Study on Entrepreneurship in a Business Ecosystem}

\section{Marikka Heikkilä and Leni Kuivaniemi}

Each of the ecosystem sub-sectors shown in Figure 3 is described in greater detail below, in the form of implementation advice for business leaders attempting to construct similar business ecosystems:

1. Technological change: Perhaps the majority of new business models build on technology or information technology. Decreasing information and communication costs make totally new processes and ways of working possible. In addition to proving new business possibilities, it also challenges the existence of current ones. Therefore, identify the potential technologies for your business and contact the suppliers.

2. Research insights: In addition to the business aspects, the ecosystem should attract research. The salience of the symbiotic relationship of business and research may be seen in Silicon Valley (Sydänmaalakka, 2011; tinyurl.com/d8c64bo). Take the time to read major research articles on the topic of your business and contact those researchers; they can help to locate suitable collaborators within the universities or other research institutes.

3. Changes in customer demand: Consumption patterns and "fashion" are examples of changes in customer demand. High adoption rates of social media is a good example of social change that might provide new possibilities. Customer co-creation is increasingly adopted to gain knowledge on the changing demand.

4. Competition/co-opetition: One of the main pressures comes from competitors. In order to survive, your product or service must be cheaper, better, or quicker than that of your competitors. However, sometimes collaboration with your competitors might be needed to execute your business model. Competitors, for instance, might have some specific knowledge or capabilities that you do not have or wish to invest in. Be brave and try to turn your competitors into co-opetitors.

5. Social change: Changes in work practices, processes, culture, and social mood in general might have an effect on the business. Changes in attitudes on environmental issues, technology adoption, or outsourcing to low-cost countries can affect the business. Collaboration with various kinds of associations and societies helps to keep track of social change.

6. Policies and legal environment: Legal issues are something that you must always take into consideration. For example, be aware of the differences in work regulations between countries. New privacy laws can make the use of some business models illegal. Many times, it pays to find out the legal restrictions at the beginning so you take them into account when building the ecosystem.

We suggest that when considering the expansion of the ecosystem, one should carefully consider all the six subecosystems recognised in Figure 3 and plan in what order the sectors should be covered. Our research so far has already revealed that there are significant differences in the clockspeed of the sub-ecosystems and this should be taken into account in planning. The clockspeed characterizes the general velocity of change in the sector and the pace of the firms' internal operations (Mendelson and Pillai, 1999; tinyurl.com/d9ov3cz). It can be measured by the rate at which new products, processes, and organizational structures are introduced. We have tentatively placed the sectors in their clockspeed order: the fastest is the technology sector and the slowest is policies and legal environment. This has practical implications; the sectors where one is most likely to find actors that are willing to cooperate in new, innovative initiatives are the technology and research sectors. In contrast, because no quick changes are expected to accrue in legal and social environments, a business initiative can build on the current laws and social customs. However, one should always be aware of the status of preparations of new laws and policies, and act accordingly.

\section{Conclusion}

This article presents early results from an ongoing action research study on a business ecosystem. The business case examined is physical activity prescription, an innovation in the field of preventive healthcare. An entrepreneur is pushing the business initiative forward. His goal is to create a functioning business network consisting of companies that jointly provide health prescription services - profitably. Together with other actors that provide and co-create supplementary services, products, and research in cooperation with public institutions, these organizations form the ecosystem.

We suggest that the expansion of an ecosystem can be analysed and even perhaps planned by considering six differing sub-ecosystems: technology, research, customer demands, competitors, social environment, and legal and policy environment.

In the future, we will work to widen the case network together with the growth entrepreneurs, corporations, as well as by teaming with researchers from different 


\section{An Action Research Study on Entrepreneurship in a Business Ecosystem}

fields. Thus, in the future, the business and research network will serve as a platform onto which the ecosystem is built one piece at a time. The use of this approach can be seen in its grander form in Silicon Valley, but whereas there it has developed over a longer period of time and without guidance, our aim is to proactively find the best-fitting components for the ecosystem to flourish.

The ecosystem is built on trust and benefit for all the participants. In the business world, the gains have to be measurable and arrive quite quickly. On one hand, this pressure creates challenges for action research, but on the other hand, it rewards the research team because we receive immediate feedback on our input. Our research hypotheses either work in a real market situation or they do not. If they do, our research will have wider meaning and impact for society both in terms of health and growth venturing.

\section{About the Authors}

Marikka Heikkilä, PhD. Econ., is project manager at the University of Jyväskylä. She serves as a coordinator of several national and international projects. Her areas of interests are business networks, business models, and coordination of complex operations. Outside the university, she is an active entrepreneur. Previously, Marikka has worked as lecturer, assistant professor, and researcher at the Helsinki School of Economics and at the Faculty of IT at the University of Jyväskylä.

Leni Kuivaniemi, $\mathrm{PhD}$. Econ., is currently working as a project manager in the Jyväskylä School of Business and Economics (JSBE). She is also partner and manager in two growth ventures. Leni has strong experience in sales, entrepreneurship, and growth venturing, both in teaching and practice. Previously she has worked as an assistant professor and a program co-director at JSBE. Leni also holds a master's degree in law from the University of Helsinki.

Citation: Heikkilä, M. and L. Kuivaniemi. 2012. Ecosystem

Under Construction: An Action Research Study on

Entrepreneurship in a Business Ecosystem. Technology

Innovation Management Review. June 2012: 18-24. 